\title{
TÍTULOS EM NOTÍCIAS DE DIVULGAÇÃO CIENTÍFICA: ESTRATÉGIAS DISCURSIVAS E FUNCIONALIDADES NA INTERFACE DO FACEBOOK
}

\author{
Lafayette Batista Melo* \\ Instituto Federal de Educação, Ciência e Tecnologia da Paraíba \\ Unidade Acadêmica de Informática \\ João Pessoa, PB, Brasil
}

\begin{abstract}
Resumo: $O$ objetivo do trabalho é compreender, através do conceito de aforização, como funciona a circulação de títulos de noticias de divulgação científica no Facebook. Foram coletados títulos por meio de técnicas de busca específicas no Google. Os resultados mostram que, em termos de funcionalidades da interface, algumas notícias são destacadas por seções específicas, pelo uso de imagens e pela edição de títulos. Em relação às estratégias discursivas, informações podem ser destacadas, tomando amostras como generalizações, garantindo informações como comprovadas, com pequenas mudanças de termos nos subtítulos e mudando o viés do texto original dos blogs nas suas replicações no Facebook. Algumas conclusões: funcionalidades e estratégias discursivas atuam em conjunto para reforçar ditos; possibilidades de circulação da informação se diferenciam não apenas em relação ao mundo fora do digital, mas em relação à história recente da Web, e funções do discurso da mídia são preponderantes para modificar informações originais.
\end{abstract}

Palavras-chave: Título. Aforização. Circulação. Divulgação científica. Facebook.

\section{INTRODUÇÃO}

Notícias sobre ciência e tecnologia se multiplicam cada vez mais em espaços diversos. Pode-se ler um artigo científico, mas também entrevistas com cientistas sobre um assunto em pauta. Pode-se comprar uma revista de divulgação científica nas bancas ou ler artigos de opinião de outros cientistas que não participaram da pesquisa fonte. Pode-se ver esclarecimentos de jornalistas sobre assuntos polêmicos ou resumos de como determinados fenômenos funcionam. As pessoas podem até mesmo se basear em títulos de notícias dos representantes da literatura de divulgação científica e divulgá-los em redes sociais. Isso faz com que as notícias se multipliquem ainda mais. A diferença é que as discussões e polêmicas geradas podem surgir intensamente em torno desses títulos e não com muita discussão sobre o conteúdo dos artigos científicos originais nem mesmo sobre o conteúdo das revistas de divulgação.

Não é apenas o cientista ou a mídia jornalística que fazem circular um discurso, mas os próprios usuários das redes sociais, que o disseminam não apenas fazendo

\footnotetext{
* Doutor em Psicologia Cognitiva pela Universidade Federal de Pernambuco. Professor de Informática. Pesquisador de Linguagem e Interação Humano-Computador. Coordenador de Pesquisa em Informática na Educação do Núcleo de Aprendizagem Virtual (NAV). E-mail: lafagoo@gmail.com
} 
referência a fontes, mas o comentando, compartilhando, curtindo e respondendo a comentários. Um discurso, que surgiria da ciência e teria certo enfoque da mídia para ser trabalhado e atingir o sujeito comum, envolve múltiplas camadas de reconstrução. $\mathrm{O}$ próprio cientista, que sai do âmbito no qual a linguagem é praticamente apenas compreendida entre seus pares especialistas para formular a escrita de um artigo, precisa escolher alguns termos, frases, períodos, analogias e comparações e esquecer outros. $\mathrm{O}$ usuário comum da internet pode moldar o título de uma notícia com um comentário, enfocando determinado aspecto do assunto que pode servir como argumentação de discussões anteriores ou mostrar impactos sociocientíficos de temas dos quais gosta. Além disso, os propósitos na divulgação são vários: esclarecer um fato científico didaticamente, defender uma ideia política ou convicção sobre temas da área de saúde com base em um raciocínio científico, divulgar um produto, vender informações sobre assuntos em alta ou polêmicas do momento etc. De todo modo, sempre se tem a noção de que, mesmo com todas as reconstruções, o discurso original de respaldo seria o científico, que confere um status de autoridade para discussões de diversas naturezas.

Este trabalho mostra o modo como o discurso de divulgação científica se propaga no Facebook, especialmente a partir de títulos de notícias que os usuários fazem circular na rede, incluindo as próprias páginas ou perfis de instituições de divulgação científica, notadamente as jornalísticas. Apesar de essas informações circularem distante da fonte original, é notável o quanto se popularizam, principalmente através dos títulos e muitas vezes rendendo discussões que nada têm a ver com a fonte original dos dados. Um exemplo desta situação é o do site Globo News em Pauta ${ }^{1}$ que publicou uma reportagem com o título "Cientistas criam minhoca resistente para entender alcoolismo entre humanos". Contudo, os cientistas entrevistados não falavam que pretendiam compreender o alcoolismo, mas apenas que estudavam modificações genéticas das minhocas e seus efeitos sob o álcool. Isso rendeu discussões em comentários do Facebook em que se dizia que a cura para o alcoolismo já teria sido descoberta, embora os cientistas ainda estejam planejando possíveis experimentações com ratos para só depois investigarem se vale a pena fazê-las com humanos. Muitos dos títulos escolhidos para divulgação começam com "Cientistas descobrem/inventam/criam/provam...", o que já é um indício de como certos discursos são formados na ponta da cadeia representada pelos usuários do Facebook. Contudo, há outras seleções que envolvem textos do tipo "Descubra como...", que pode ter como complemento informações sobre saúde, aprimoramento intelectual ou sexual e questões que procuram tirar dúvidas sobre informações bastante discutidas na atualidade (pode ser desde como se livrar de um vírus ou detalhes de personagens de filmes, entre outras).

O que importa para este trabalho é investigar e mostrar como esses discursos, que partem apenas de títulos, estão articulados com o suporte virtual, ou seja, com a interface do Facebook, envolvendo o grau de desenvolvimento tecnológico atual, os recursos linguísticos e o momento histórico. Para isso, o trabalho se utiliza de conceitos sobre aforização de acordo com Maingueneau (2008, 2010, 2014 e 2015) e de pesquisas anteriores em análise do discurso que conferiram importância à interface do Facebook,

\footnotetext{
$1 \quad<$ http://globotv.globo.com/globo-news/globo-news-em-pauta/t/todos-os-videos/v/cientistas-criamminhoca-resistente-para-entender-alcoolismo-entre-humanos/3505104/>
} 
de forma a compreender suas peculiaridades como em Melo (2014a, 2014b e 2015). Em outras palavras, investiga-se o modo como componentes e funcionalidades da rede influenciam o discurso e o modo como este discurso se apropria do suporte para fazer circular determinadas informações tidas como tácitas, graças a um suposto embasamento de uma autoridade científica, construído alhures. Algumas perguntas de pesquisa que se pretende responder após a análise dos dados: 1) o uso das funcionalidades e dos componentes da interface atuam em conjunto ou separados de um determinado discurso que os usuários do Facebook fazem circular?; 2) os discursos analisados neste trabalho têm diferença de outros discursos semelhantes que estejam na Web, mas não na rede social? e 3) há um novo discurso produzido na rede diferente do que é realizado pelos órgãos de divulgação científica?

Para o desenvolvimento deste artigo, são mostradas algumas considerações do que seria um discurso científico, segundo opiniões de diferentes autores, listando também o que, em um primeiro momento, poderia ser considerado um modo próprio de sua circulação na rede social. Em seguida, são discutidos alguns conceitos para a abordagem teórico metodológica deste trabalho: aforização, configuração contextual, interação humano-computador-humano e interação para si. É ressaltado, na seção posterior, o método de coleta dos dados, que é de particular importância para a constituição do corpus deste trabalho, já que não obedece aos limites dos materiais físicos impressos e cuja produção é volátil e está fora do controle do analista. Na parte principal, são mostrados os resultados concomitantemente a análises que indicam categorias que se ressaltaram no trabalho. Ao final, há algumas constatações e possíveis orientações para responder às perguntas da pesquisa.

\section{ESPAÇO DO DISCURSO DE DIVULGAÇÃO CIENTÍFICA E SEUS DIFERENTES MODOS DE SER VISTO E PRODUZIDO}

Não é de hoje que há preocupações e estudos sobre a divulgação científica. Para Authier-Revuz (1982), o discurso de divulgação científica estaria nada mais nada menos do que no campo da reformulação. Ou seja, seria um outro discurso científico, teria uma certa equivalência com este, mas não seria exatamente de outra natureza. A divulgação científica estaria no intermediário entre a ciência e divulgação para parte da população que não tem conhecimentos científicos específicos. Haveria uma estruturação do tipo "eu (divulgador) digo a vocês (público leigo) que eles (cientistas) dizem".

Grigoletto (2005) faz alguns questionamentos sobre essas concepções e diz que há um novo discurso, mas não no sentido das rupturas e (re)formulações. Está na ordem de um deslocamento que mantém uma ressonância com o discurso da ciência. Dentro desta ordem, há um espaço intervalar cujas fronteiras são delineadas nos entremeios da mídia, da ciência e do leitor. Por isso, para Grigoletto (2005), esse discurso agrega tanto o novo pelo modo de dizer quanto ressoa o antigo, discursivizando o já-dito nos parâmetros da ciência. Para Zamboni (2001), existe realmente um discurso novo, que estaria na ordem de um diferente discurso de transmissão de informação, não poderia ser compreendido como apenas reformulação. Grigoletto (2005) contesta tal concepção, pois na análise do discurso não se poderia considerar o discurso como transmissão de informação ou como 
se os sentidos fossem transferidos do locutor para o interlocutor diretamente. A autora, contudo, não acredita que haja apenas duas formas de discurso envolvidas - a científica e a jornalística -, mas um discurso do senso comum, ou seja, do leitor de divulgação científica. Orlandi (2001) diz que o jornalista diz em um discurso e diz em outro, que há um duplo movimento de interpretação, com efeitos do jornalismo científico. A divulgação científica seria a textualização do discurso científico em sua forma jornalística. Grigoletto (2005), porém, não discorda totalmente dos demais autores, mas acrescenta que as reformulações discursivas não são transferências, pois não há só formulação mas também repetições e paráfrases. O discurso de divulgação científica é entendido pela autora como um deslocamento, onde há comentários, fala-se de crenças, imaginações e são dadas opiniões. Isso ocorre porque já um direcionamento para o discurso de senso comum, do leitor da divulgação que também é sujeito em todo o processo de discursivização.

Este trabalho considera as reflexões de Grigoletto (2005) para compreender especificamente como já estão circulando notícias de divulgação científica nas tecnologias de interface das redes sociais. O interesse pela ciência tem aumentado bem como as preocupações sobre como fazer divulgação científica através das novas tecnologias. Kishie (2015) diz que a divulgação passou a ser uma exigência de muitas bases de indexação, como a SciELO a exemplo de periódicos internacionais que publicam em portais como EurekaAlert!. Entre as exigências, há também o desenvolvimento de materiais para redes sociais como Twitter, Facebook, Academia.edu, Mendeley e ResearchGate, entre outros. Muitas revistas constroem páginas para serem divulgadas no Facebook e até adequam seu conteúdo para leitura em dispositivos móveis. Contudo, nenhuma instituição de divulgação tem controle sobre quais conteúdos os usuários de uma rede social compartilham e muito menos como enfocam o conteúdo.

Apesar dessas preocupações do "fazer" da divulgação e de já termos reflexões sobre o discurso da divulgação científica, este trabalho mostra como já está ocorrendo a divulgação pelos sujeitos usuários do Facebook. Na concepção deste trabalho, este sujeito não é meramente um usuário que está interagindo na rede, mas um sujeito histórico que está envolvido na tríade ciência-jornalismo-cotidiano. Há um leitor importante na ordem do discurso, como diz Grigoletto (2005), mas este sujeito leitor-usuário nas redes sociais também faz circular discursos para outros leitores e, principalmente, através de títulos que extrai de notícias para confirmar, discordar ou disseminar assuntos dos quais gosta. Esse leitor utiliza-se de títulos, mas que algumas vezes vêm acompanhados de subtítulos, gráficos ou imagens. Ele não apenas lê, mas também tem o poder de divulgar com simples curtidas e enquadrar o assunto conforme seus propósitos, seja para refutar uma ideia antes estabelecida ou para "interagir" com seus interlocutores. É esta a especificidade deste trabalho, que procura contribuir para entender um fenômeno atual no qual as pessoas estão cada vez mais engajadas A abordagem teórico-metodológica com alguns dos seus conceitos é descrita na próxima seção, de modo a se ter um arcabouço mais aprofundado para o que seriam esses títulos no discurso e sobre qual é o papel do suporte da interface computacional. 
3 ABORDAGEM TEÓRICO-METODOLÓGICA: AFORIZAÇÃO, CONFIGURAÇÃO CONTEXTUAL, INTERAÇÃO HUMANO-COMPUTADOR-HUMANO E INTERAÇÃO PARA SI

Atualmente, as pesquisas em Análise do Discurso ganharam novos reforços teóricometodológicos. Por meio do conceito de aforização, Maingueneau (2014) ressaltou modos de como pequenos textos têm sido produzidos na sociedade. O autor começa sua investigação através do que chama destacabilidade. Não seria apenas a constatação de destacamento em partes de um texto, mas de considerar como este texto se apresentava antes do destacamento. Seria o caso de reportagens que reproduzem trechos entre aspas de determinados enunciadores, mas sem considerar, no título, as condições em que esses trechos foram produzidos.

Outro conceito de Maingueneau (2014, 2008, 2010) é o de sobreasseveração, que seria uma antecipação do destacamento. Assim, em uma declaração do então candidato à presidência da França Nicolas Sarkozy, na qual ele utilizou várias vezes a frase "Eu mudei", o destaque na reportagem escrita ainda apresentava a expressão em itálico ( "Eu mudei"). Isso indicaria como a mídia recorta seus fragmentos, privilegiando ou minimizando a interpretação de determinados discursos. Outras formas de sobreasseverar ocorreriam no emprego de aspas, discurso direto ou indireto, posicionamento das frases ao final de parágrafos ou de forma sentenciosa em títulos, na junção de duas frases dispersas em um texto como sendo um enunciado só (destacado no meio de uma entrevista, por exemplo) etc. O conceito de Maingueneau $(2014,2010)$ mais debatido atualmente é o de aforização. O pesquisador parte das destacabilidades e sobreasseverações para mostrar que determinadas frases seriam produzidas com uma convicção diante do mundo, que se quer rica de sentido para todos. O enunciado aforizante se dá ao mesmo tempo como memorável e memorizável. Porém, há também aquelas aforizações que não resultam necessariamente da destacabilidade, que seriam as aforizações primárias (provérbios, adágios, divisas, slogans etc.).

As aforizações tendem a ser mais ou menos aceitas, a ficar mais ou menos impregnadas. Este trabalho especifica como funcionam enunciados aforizantes destacados de textos (no caso, títulos que podem ser destacados dos artigos científicos ou das notícias de divulgação científica). Para Maingueneau (2010), a enunciação tem duas ordens: aforizante e textualizante (mais fortemente ligada a um gênero discursivo). A enunciação aforizante pode ser destacada por natureza (um provérbio, por exemplo) ou destacada de um texto (no caso, títulos). Maingueneau (2014) trata de vários modos de destacamento: posições salientes (início ou fim de seções, por exemplo), valores generalizantes, estruturas pregnantes (metáforas, simetrias), metadiscurso (com retomadas - "esta verdade..." - ou conectores (“enfim”, “digamos”). Há ainda vários exemplos do autor que mostram uso de aspas, seleção de partes de resposta de uma entrevista para servir como títulos de seções e até o modo como os rostos juntos com os títulos provocam certos efeitos. O sujeito, em cada momento histórico, dispõe de gêneros e recursos diversos para fazer as suas formas de destacamento.

Considerando que tais destacamentos têm uma gama de recursos e, consequentemente, estratégias próprias para serem utilizadas, este trabalho se utiliza de alguns conceitos que procuram compreender mais a relação deste sujeito usuário das 
redes com o suporte, que não é só o que porta o texto, mas o que pode estar imbuído de outros efeitos de sentido. Assim, compreende-se neste trabalho a expressão interação humano-computador-humano, ao invés de interação humano-computador, de modo a ressaltar os efeitos produzidos socialmente. Além disso, o "humano" do qual tratamos pode ser tanto uma pessoa postando e conversando com outra dentro da sua timeline quanto uma empresa, como um jornal ou uma revista, cuja página é lida pelo sujeito leitor, que, de certa forma, também é um produtor. O texto não é transparente, as imagens não são transparentes, o discurso não é transparente e o uso dos componentes da interface também não é. Assim, compreender a influência desses fatores em conjunto é primordial hoje em dia, mas, em uma perspectiva discursiva, o discurso é visto como anterior aos demais planos. Em outras palavras, tratar da interação humano-computador-humano enseja a uma orientação para que o pesquisador considere os componentes da interface, mas não necessariamente e exclusivamente o design, os aspectos semióticos ou sua possível gramática e textualidade.

Na interação humano-computador-humano sempre se considera que há a priori um discurso ao qual os sujeitos se vinculam e que acionar ou ler componentes como botões, links, campos de formulário, comentários e postagens está dentro de um conjunto de ações orientadas também para um discurso, seja para defendê-lo, atacá-lo, silenciá-lo ou ressaltá-lo. Portanto, tratamos aqui não de usuários em interação com a interface, mas de sujeitos que procuram se associar ou fugir de determinados discursos ao operacionalizar esta interface. Isso eles só podem fazer se considerarem que há sempre um humano do outro lado que é um sujeito histórico. Tal tipo de prática parece própria para as redes sociais, pois mesmo em blogs da Web não havia esse modo de produção e reprodução material. Decorre daí a configuração contextual, que é o modo como as pessoas percebem, usam e gerenciam as configurações dos seus ambientes quando interagem publicamente em formatações, comandos e habilitações, Melo (2015).

Tanto no ambiente físico quanto nos sistemas, não temos apenas "configurações" a serem investigadas e que podem ser habilitadas ou desabilitadas para uma completa investigação das possibilidades de interação. Essas possibilidades se fazem no uso dos ambientes sociais virtuais ou físicos e podem depender muito das habilidades e dos interesses que as pessoas têm no momento ou do que pretendem negociar, ou melhor, do discurso nos quais estão inscritas. Portanto, o mais importante não é a configuração exata do ambiente, no sentido de haver ou não um conjunto de opções ativadas, mas como as pessoas percebem, usam e gerenciam essas configurações quando pretendem interagir umas com as outras. Por exemplo, em uma conversa no bate-papo no Facebook, sabemos quando o outro está disponível se aparece um sinal verde, mas também podemos enviar uma mensagem na expectativa de que a outra pessoa esteja on-line, mas não visível no Facebook, ou mesmo para que responda em outro momento, já que a mensagem chegará supostamente de qualquer maneira.

A partir da interação humano-computador-humano e da configuração contextual pode-se observar uma "interação para si” no Facebook: as ações são sempre relacionadas a postagens ou notificações da plataforma da rede, o que chama sempre à monitoração de quem postou. A interação para si é a propriedade que o sujeito tem de agir com o outro, mas essencialmente voltando-se para si através da interface. Há uma ação na interface 
que envolve não apenas como as pessoas compartilham textos, imagens e links, mas como desenvolvem uma série de ações. O usuário pode até crer que está no controle de suas ações, "interagindo" com quaisquer outros, mas a interface também o direciona a discursos específicos, quando postagens que aparecem no topo são as mais relacionadas a assuntos que ele visualiza e quando tudo que ele diz volta mais para si próprio do que é direcionado para esses outros, já que ele é sempre notificado sobre curtidas, compartilhamentos e comentários de sua postagem, sem contar a expectativa gerada para si mesmo, de acordo com Melo (2015).

Os conceitos apresentados também têm consequências para o modo como os dados são coletados, o que é detalhado na próxima seção.

\section{COMO OS DADOS FORAM COLETADOS}

O corpus discursivo não é um conjunto fechado de dados que emergem de uma certa organização. Há etapas sucessivas de trabalho sobre os corpora ao longo de toda a pesquisa. Maingueneau (2008) propõe análises a partir do conceito de percurso, no qual os dados circulam intensamente e, ao mesmo tempo, podem ter suas buscas otimizadas com o uso de ferramentas computacionais específicas, em diversas ordens lexicais ou textuais não pré-formatadas. Para fazer a busca dos títulos, mas compreendendo que não estão isolados e sim associados a imagens e modos diferentes de serem proliferados (em geral, vêm de blogs e sites ou páginas oficiais do Facebook de órgãos de divulgação científica), foi adotado o conceito de percurso, de acordo com Maingueneau (2014), e foram feitas adequações para os objetivos deste trabalho com usos do Google Search, do Graph Search do Facebook (ferramenta de busca da rede que aparece no quadro superior à esquerda quando o ambiente é configurado para o idioma em inglês) e das estratégias específicas de busca conforme Melo (2014a, 2014b), como a de busca de postagem por data nas páginas do Facebook - mas através do Google Search, o que otimiza as pesquisas mais do que no próprio Facebook . As etapas envolvem:

1 - definir dois exemplares a serem seguidos de páginas oficiais de divulgação científica (Galileu e Superinteressante);

2 - uso do Google Search para encontrar postagens de títulos sobre ciência compartilhadas de diferentes usuários (amigos ou não do analista pesquisador);

3 - encontro de postagens peculiares e categorizáveis conforme a estratégia de destacamento dos sujeitos usuários;

4 - reavaliação das pesquisas e novas buscas para otimização dos dados, o que perfez mais de 180 resultados, uma parte não muito diferenciada (em geral as que partem das páginas oficiais dos órgãos de divulgação), mas uma outra parte (essencialmente moldada por diferentes usuários) que mostrou características analisadas a seguir. 


\section{RESULTADOS E ANÁLISE: O EFEITO DOS TÍTULOS DE DIVULGAÇÃO CIENTÍFICA EM REDE}

Os exemplos colocados adiante referem-se a categorias cujas peculiaridades foram assinaladas, mas que se ressaltaram, conforme os dados e a configuração contextual adotada, envolvendo mais ou menos as funcionalidades da interface e as estratégias discursivas às quais os sujeitos usuários se vinculam.

\section{Figura 1 - Divulgação sobre defensivos agrícolas}

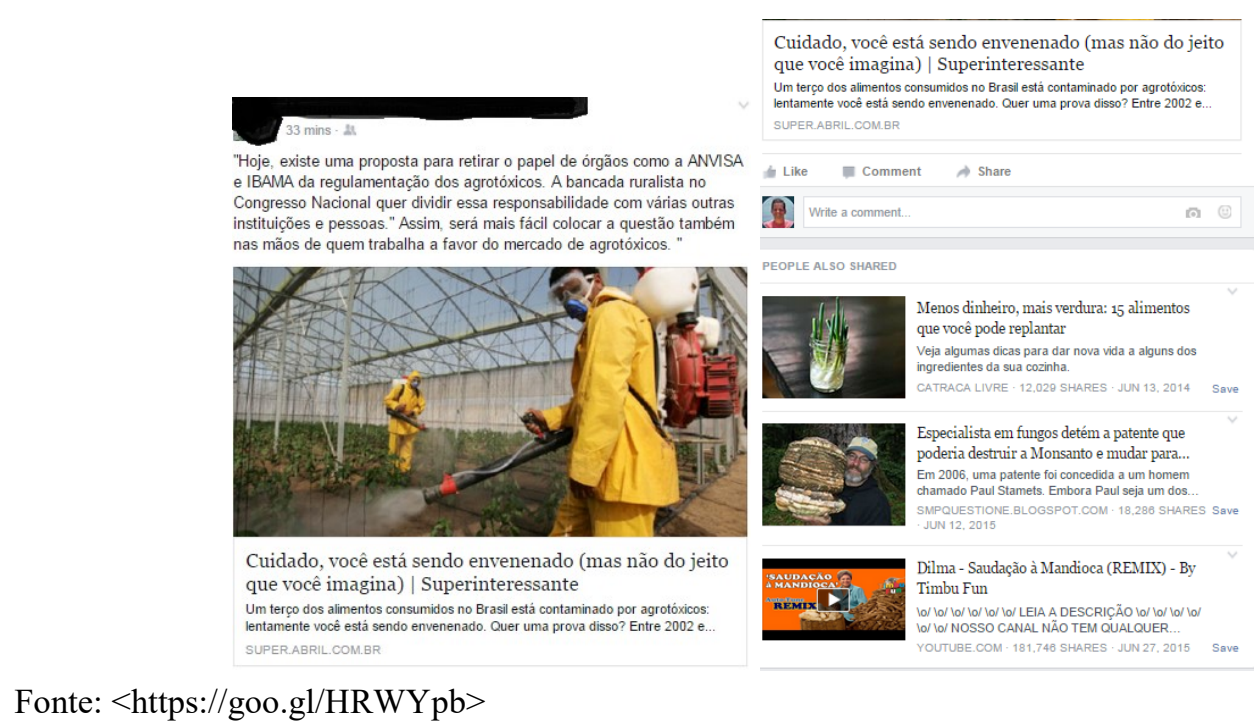

Como se pode observar na figura 1, o título da reportagem é veiculado no Facebook por um usuário que ainda o comenta na postagem. O título fala do cuidado com o uso de agrotóxicos (há um chamamento em suspense no título e a relação com agrotóxicos no subtítulo) e o comentário alerta sobre a possibilidade de a ANVISA e o IBAMA perderem suas funções. O sujeito usuário acrescenta que questões sobre o mercado de agrotóxicos pode ficar sob os cuidados da bancada ruralista, o que implica satisfazer seus próprios interesses comerciais. Salienta-se que grande parte dos comentários da postagem não se referem tanto ao cuidado com os materiais químicos, mas sobre questões políticas e interesses que políticos e empresas têm de manter o poder sobre uso e venda desses materiais.

Os sujeitos que comentam a postagem se direcionam mais a favor do comentário principal da postagem, citando e acusando diretamente vários outros políticos e empresas. O Facebook disponibiliza esse conjunto de informações para curtidas, compartilhamentos e acréscimo de comentários, mas também coloca sugestões de reportagens selecionadas na seção "People shared" (outras pessoas que compartilharam isso também compartilharam...). Nesse caso, há um link sobre dicas de replantio e outro sobre pendengas com a empresa de agricultura e biotecnologia Monsanto. Não são todos os links que produzem um efeito no mesmo teor do discurso que o sujeito usuário quis imprimir na postagem. A sugestão do link sobre replantio talvez só tenha uma associação 
com o fato de se falar sobre "plantas", termo que provavelmente o Facebook ligou às sugestões, além de outras pessoas terem compartilhado as postagens. Isso mostra que a sugestão do Google sempre tem a possibilidade de se aproximar do discurso envolvido, mas não há qualquer garantia de reforçar todas as sugestões no que o usuário deseja de uma "interação para si".

A enunciação aforizante com destacamento de um texto no título mostra-se na organização com layouts e funcionalidades descritos com origem em uma reportagem do site da Superinteressante, mostrado na figura 2.

\section{Figura 2 - Reportagem original}

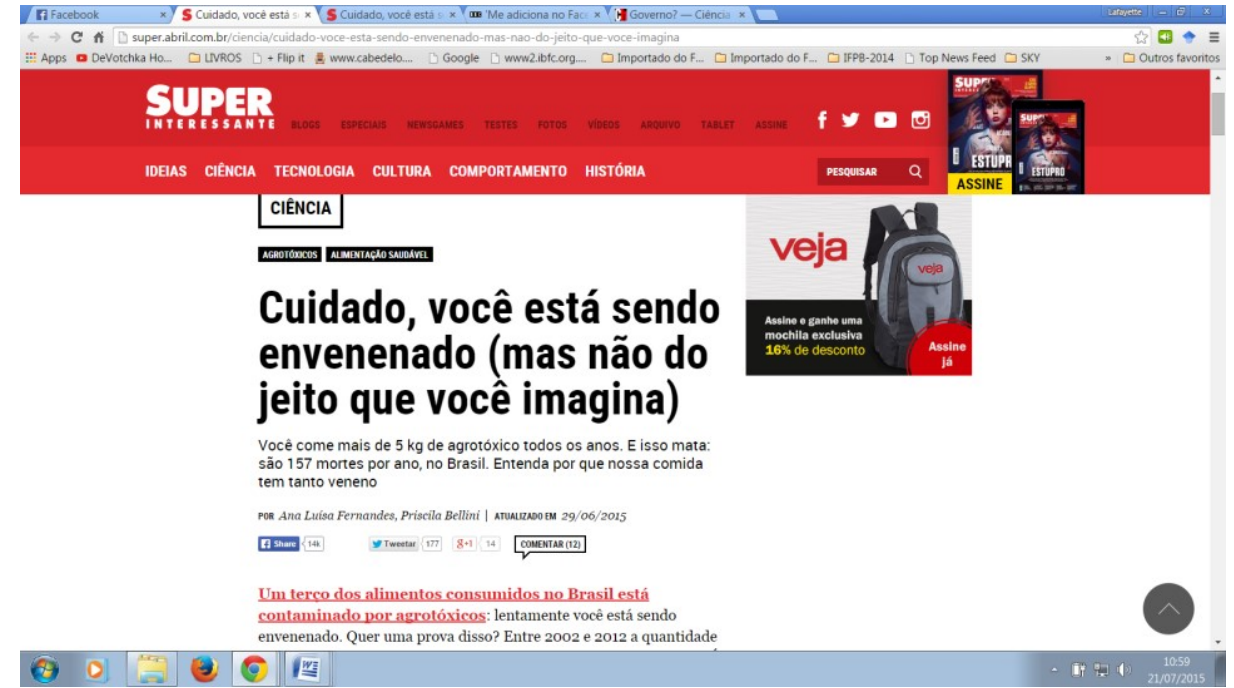

Fonte: <http://super.abril.com.br/ciencia/cuidado-voce-esta-sendo-envenenado-mas-nao-do-jeito-quevoce-imagina $>$

Há o mesmo título na postagem e no site da revista. Porém, os subtítulos têm teores diferentes e as imagens são usadas de diferentes modos. No site, não há destacamento da imagem e o subtítulo fala do quanto comemos de agrotóxico e por que isso acontece no Brasil. Na postagem, o subtítulo fala do quanto estamos sendo envenenados e há uma imagem de um indivíduo com máscara, borrifando a substância, o que sugere periculosidade. Associados ao comentário do sujeito postador, subtítulo e imagem ganham não só acentuação no grau de periculosidade, mas denúncia direta a certos grupos, reforçando riscos para o ser humano em proveito do interesse econômico. $\mathrm{O}$ aforizador diz como se estivesse em um plano universal, angariando os recursos da rede para imprimir seu discurso. Não se pode negar que há circulação da divulgação científica, mas também é notável o quanto a afiliação discursiva do leitor constrói um modo de circular notícias. Ele deixa de ser apenas leitor, é divulgador a seu modo, dentro das limitações e possibilidades da configuração contextual da plataforma.

Enfim, há vários exemplos desse tipo, que mostram como, em termos de funcionalidades da interface, algumas notícias de divulgação científica podem ser reforçadas, aumentando ou diminuindo seu teor ao modo do aforizador, através de seções 
da interface, textos que acompanham as postagens e uso de imagens selecionadas ou diferentes da notícia original.

$\mathrm{Na}$ figura 3 adiante, pode-se verificar uma intrusão maior do sujeito usuário. Uma reportagem original que trata do efeito do aquecimento global tem uma divulgação, mas com um título modificado, incluindo palavrão. No Facebook, o usuário pode editar os títulos e subtítulos, bastando que, antes de clicar no botão "postar", clique no título, que fica destacado em amarelo para edição conforme o usuário deseje. Nesse caso, há um tom de exagero e possivelmente de intenção de humor do sujeito, mas há várias outras edições que deturpam totalmente a divulgação e o fato científico. Por exemplo, há referências a links sobre doenças, com títulos que dizem que foi descoberta uma vacina ou a cura, embora nem no artigo de divulgação nem nas fontes se faça qualquer referência a isso. Tal fato indica como tantas notícias falsas proliferam. As pessoas leem só títulos, mas também muitos títulos falsos e os divulgam conforme estejam de acordo com suas crenças. O pior é que fora do Facebook há o surgimento crescente de ferramentas on-line que geram notícias falsas com cada vez maior requinte, como é o exemplo do Notícia Falsa $^{2}$ e do Notícias Fake ${ }^{3}$. Isso não quer dizer que os usuários se empenhem só em deturpar informações. Como visto nos exemplos anteriores, não necessariamente as notícias são intencionalmente modificadas, mas pode-se partir dos mesmos fatos para dar novos enquadres e teores aos discursos, com formas de destacamento específicas e uso das funcionalidades que a plataforma dispõe no momento. Assim, em termos de funcionalidades da interface, notícias podem ser modificadas, por meio de edição dos títulos e divulgação de falsas notícias.

Figura 3 - Edição de títulos
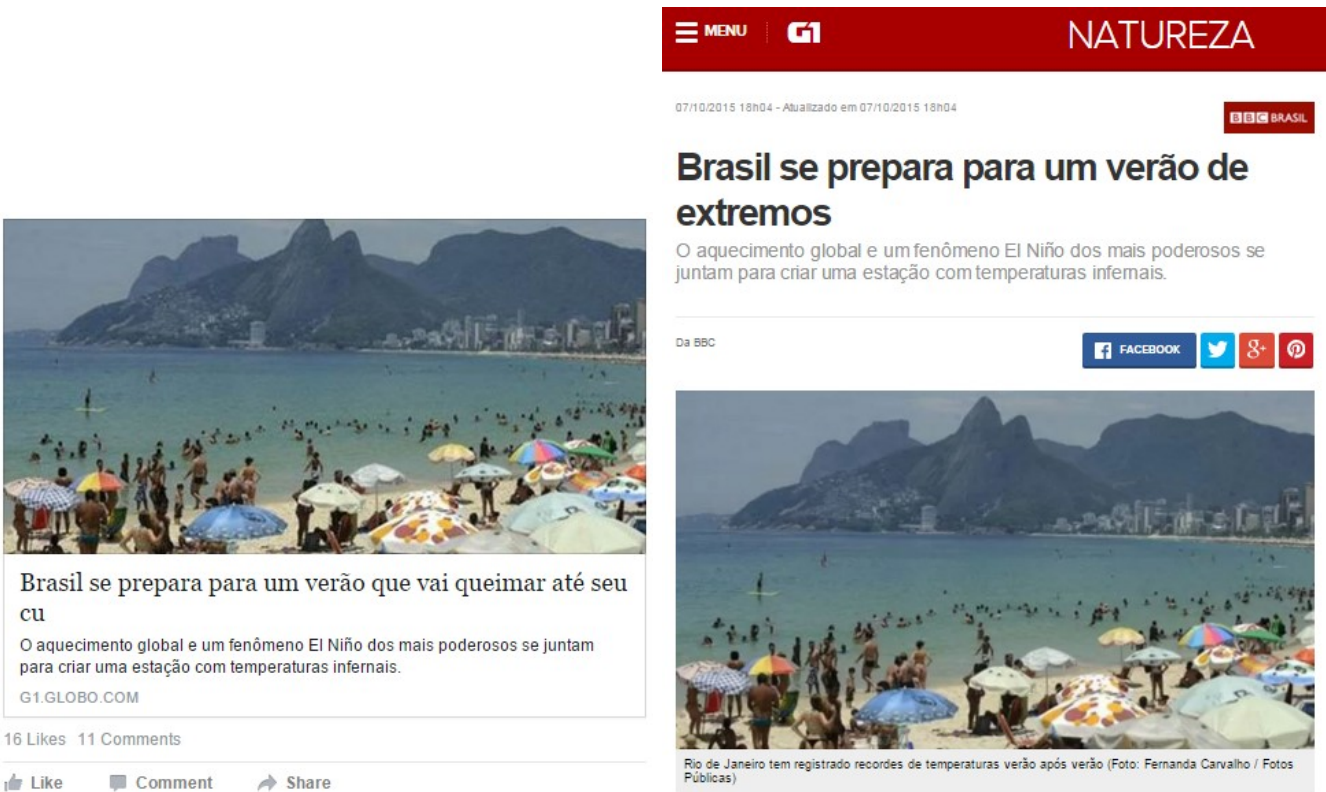

Brasil se prepara para um verão que vai queimar até seu $\mathrm{cu}$

O aquecimento global e um fenômeno El Niño dos mais poderosos se juntam para criar uma estação com temperaturas infernais.

G1.GLOBO.COM

16 Likes 11 Comments

Like Comment $\rightarrow$ Share

Fonte: $<$ http://g1.globo.com/natureza/noticia/2015/10/brasil-se-prepara-para-um-verao-deextremos.html>

\footnotetext{
2 http://noticiafalsa.com/

${ }^{3} \mathrm{http}$ ://noticiasfake.com.br/
} 


\section{Figura 4 - divulgação sobre sexo oral}

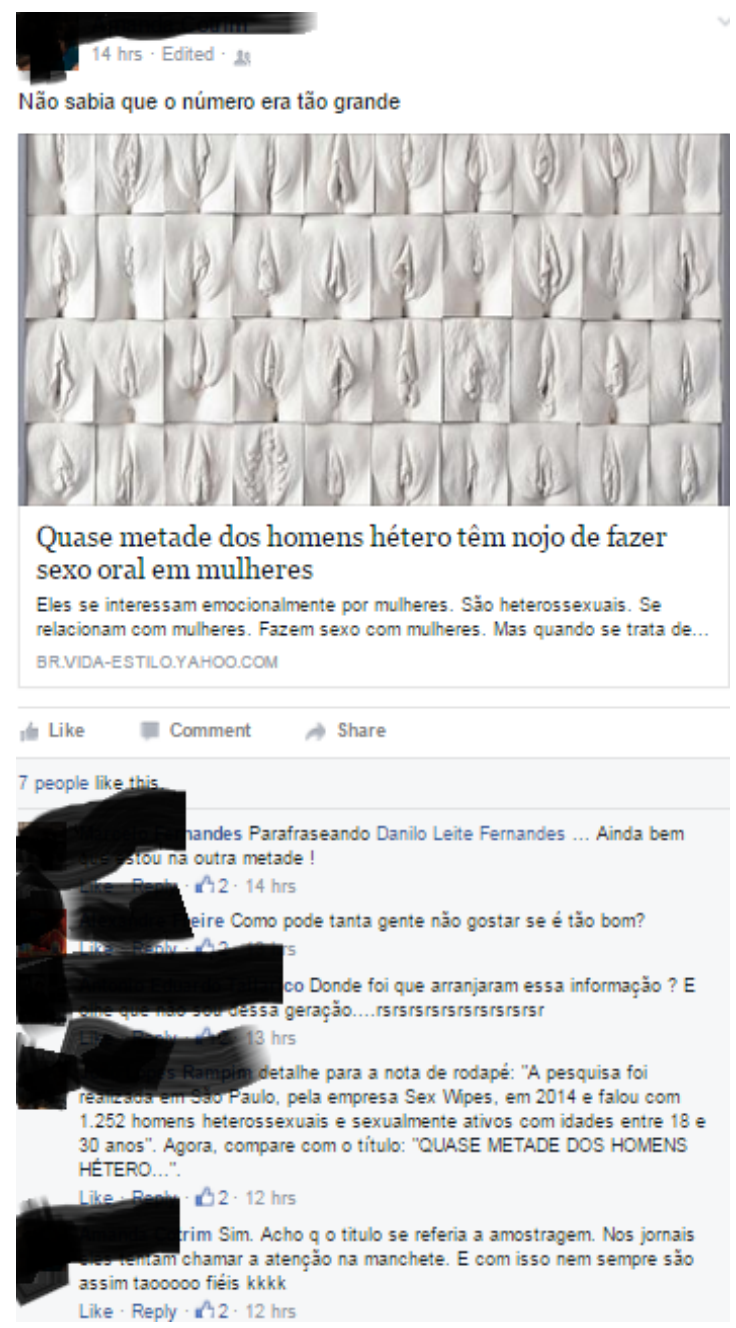

Fonte: <https://br.vida-estilo.yahoo.com/post/124570883030/quase-metade-dos-homens-hetero-tem-nojode-fazer?linkId=15695155>

Na figura 4, há uma divulgação sobre práticas sexuais dos homens e, supostamente, da grande quantidade que não gosta de fazer sexo oral nas mulheres. Nesse caso, $50 \%$ pode ser entendida como uma quantidade grande, já que essa deveria ser uma prática mais exercida, até como confirmam os comentários, muitos dos quais falando da já conhecida falta de sensibilidade dos homens e da pouca importância que dão ao prazer da parceira. Obviamente, o título com seus comentários é o que mais circula e e o que é mais lido no conjunto do artigo. Nos comentários da figura, porém, aparece um dos poucos comentários que analisa a notícia em seu conteúdo, alertando para o cuidado de a pesquisa ser realizada por certa empresa, em certo ano, com certo grupo e em certa faixa etária. Isso pode contrapor o valor que é divulgado no título, que diz de uma forma geral "quase metade dos homens", sem considerar que a experiência de outros que estão em outra faixa etária mais adiantada, por exemplo, concorreria para que a experiência tornasse esses homens mais amadurecidos sexualmente e, talvez, mudasse a estatística. O título fala dos homens em geral, mas a reportagem trata de uma amostra bem específica. Há detalhes como o do acompanhamento da imagem que pode chamar atenção pela representação de 
um órgão sexual, mas o aforizador diz do seu pedestal utilizando de tudo que pode ter de configuração contextual mais estratégias linguísticas. Em termos de estratégias discursivas, algumas notícias podem ser ressaltadas ou silenciadas conforme o grau de generalização (tomando uma amostra como generalização do universo dos dados, por exemplo).

$\mathrm{Na}$ figura 5, há uma divulgação sobre os perigos da nimesulida, começando com "Você sabia...". Algumas notícias desse tipo começam com "Conforme autor tal ou universidade tal...", "Pesquisas mostram que..", "Estudos comprovam que.." etc. Tal formulação reforça o status da notícia científica que por si só já teria autoridade. Nesses casos, as notícias são reforçadas em termos de estratégias discursivas, garantindo informações como comprovadas, sem abertura para divulgação de pesquisas que apontem para conclusões divergentes.

\section{Figura 5 - Divulgação sobre medicamento}

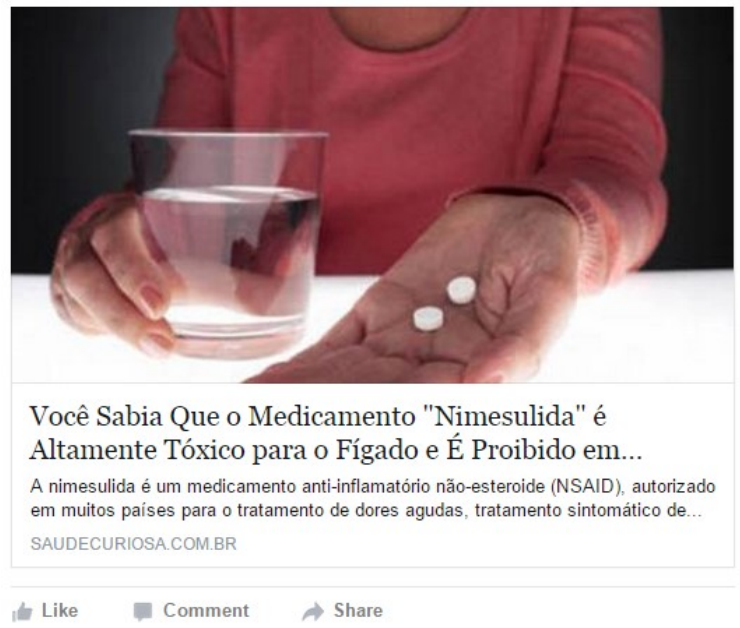

Fonte: <http://www.saudecuriosa.com.br/voce-sabia-que-o-medicamento-nimesulida-e-altamente-toxicopara-o-figado-e-e-proibido-em-varios-paises/>

Na figura 6, há um título que diz que o Google pode definir eleições, com atestado de um pesquisador. O subtítulo diz que o pesquisador afirma que resultados podem ser manipulados. O comentário do aforizador já trata da influência do Google nas eleições brasileiras. Nota-se uma gradação que vai de afirmações mais ou menos fortes, mais ou menos direcionadas (o comentário fala do Brasil, embora a reportagem não fale disso em nenhum momento) em postagens desse tipo, até incluindo verbos em campos semelhantes, mas com efeitos diferentes como "pode acontecer", "deve acontecer", "aconteceu" em diferentes seções. Podemos ver que em termos de estratégias discursivas, notícias podem ser atenuadas, divergidas, contrariadas, direcionadas em pequenas mudanças de termos nos subtítulos, títulos e comentários que podem ser identificadas em termos ou expressões com sinonímias e similaridades, embora com efeitos diferentes. 


\section{Figura 6 - Divulgação sobre o Google}

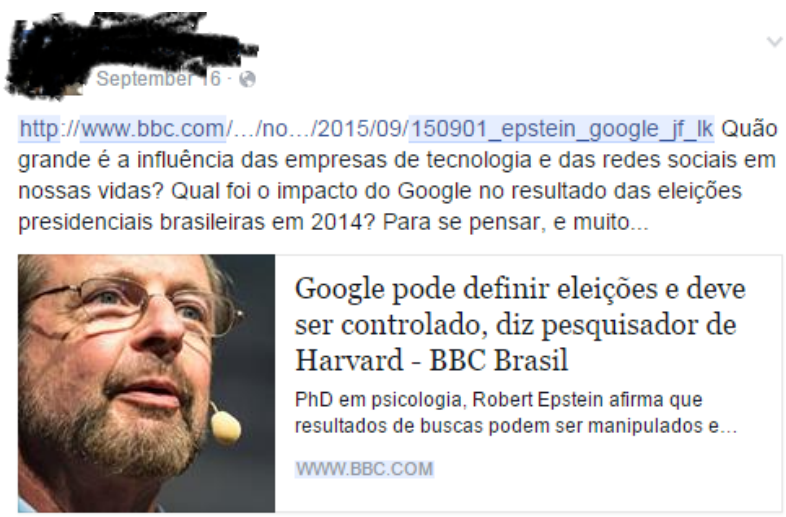

Fonte: <http://www.bbc.com/portuguese/noticias/2015/09/150901_epstein_google_jf_lk>

\section{Figura 7 - Notícia sobre "estocar vento"}

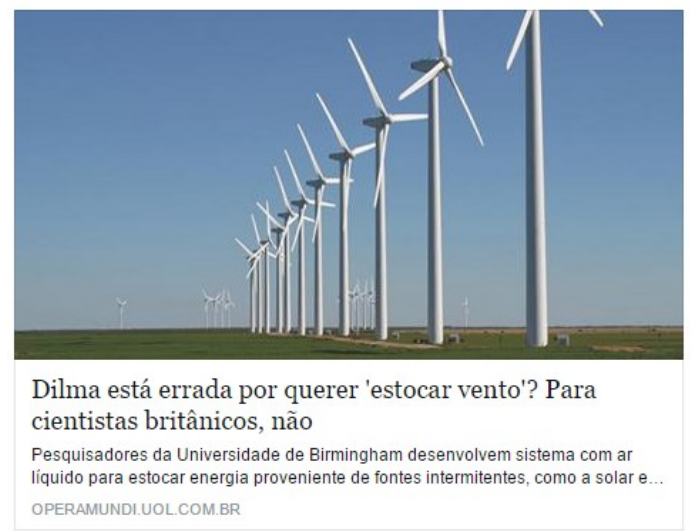

Fonte:

$<$ http://operamundi.uol.com.br/conteudo/samuel/41934/dilma+esta+errada+por+querer+estocar+vento + p ara + cientistas+britanicos + nao.shtml $>$

Temos uma notícia sobre energia eólica e o modo como ela pode ser produzida, na figura 7, acima. Há uma referência explícita a outra discussão, decorrente de depoimento da presidenta Dilma, que usou a expressão "estocar vento" e foi rechaçada, chamada de burra e ignorante pelo fato de que ninguém poderia estocar vento. A postagem claramente quer defender a presidenta, pois respalda sua fala em pesquisas de cientistas britânicos. O subtítulo, no entanto, trata de ar líquido e estocagem de energia, não de vento. Os comentários a favor ou contra a presidenta se detêm, basicamente, no fato de poder ou não estocar. Fala-se de estocagem de ar e não de vento, de ar comprimido acumulado em rochas, de armazenagem de energia como sendo o equivalente a armazenar vento, do fracasso da técnica em pesquisas nos Estados Unidos etc. Nas discussões, são colocados vários links para outros artigos e sites com opiniões de especialistas. A verdade é que no percurso do artigo fonte original para a postagem no Facebook, praticamente nada é discutido do artigo referido. O que importa é manter no Facebook justificativas para suas opiniões. Em relação às estratégias discursivas, são usadas referências de divulgação 
científica ou de artigos para defender fortemente o que foi dito antes no encadeamento de diferentes enfoques dos textos científicos originais nas replicações no Facebook para argumentar sobre outro assunto que não o científico.

Todas as enunciações aforizantes citadas, sejam mais fortemente baseadas em técnicas da interface ou em estratégias discursivas, se baseiam em um enquadramento testemunhal. Maingueneau (2015) diz que a interpretação de aforizações destacadas de um texto varia conforme o quadro em que são apreendidas. No enquadre informacional, há um fazer saber, é algo menos custoso para o intérprete, o enunciado tem um peso informacional maior do que qualquer outro. No enquadre testemunhal, tende-se a reduzir a dimensão informacional em favor da expressão de uma convicção, de uma emoção, de uma experiência. Já no enquadre acional, sujeitos aforizadores são aqueles cujas palavras têm poder de transformação da realidade. Em um primeiro momento, podemos achar até que as postagens estão dentro de um enquadre informacional, mas o envolvimento para defender ideias aparece frequentemente, como no exemplo anterior. O enquadre testemunhal pode ser sentencioso (com apagamento enunciativo, testemunho geral, ou seja, o aforizador retoma valores que devem unir a comunidade) ou ter um superinvestimento subjetivo personalizante (a aforização está centrada na expressão direta dos afetos do locutor e não na afirmação de normas coletivas). Pode-se ver em várias postagens comentadas um enquadre testemunhal fortemente sentencioso referindo-se a valores científicos corretos ou benéficos para a humanidade -, mas também investimentos personalizantes - indiciais para o fato de o sujeito usuário do Facebook estar envolvido em uma interação para si.

\section{ALGUMAS CONSTATAÇÕES}

Observa-se até o momento que as postagens com informações enviesadas ou equivocadas obedecem a um modo de funcionamento típico da mídia jornalística, sem necessariamente comprovarem ignorância ou desinformação dos divulgadores - hipótese esta bastante em voga no senso comum. Ou seja, informações com algum enfoque, viés ou grau de deturpação de forma intencionada ou não, seguem o modus operandi da mídia com suas estratégias para enquadrar a notícia. Porém, envolvidos em títulos, os sujeitos usuários acrescentam peso ao enquadre testemunhal e aprimoram estratégias próprias de comunicação possibilitadas pelas tecnologias existentes. Respondendo às perguntas da pesquisa:

1) $\mathrm{O}$ uso das funcionalidades e dos componentes da interface atuam em conjunto ou separados de um determinado discurso que os usuários do Facebook fazem circular? Atuam em conjunto, com maior ou menor grau, mas não se pode dizer em nenhum caso que algo foi dito ou silenciado unicamente pelo discurso ou simplesmente pelo uso da interface.

2) Os discursos analisados neste artigo têm diferença de outros discursos semelhantes que estejam na Web, mas não na rede social? As possibilidades de circulação da informação se diferenciam não apenas em relação ao mundo fora do digital, mas em relação à história recente da Web - nem em blogs nem em ambientes virtuais de aprendizagem se vê o modo de circulação apresentado no Facebook. 
3) Há um novo discurso produzido na rede diferente do que é realizado pelos órgãos de divulgação científica? De modo semelhante a Grigoletto (2005) que não nega a divulgação científica como textualização do discurso científico, mas que diz que as reformulações discursivas não são transferências, são mais deslocamentos com suas repetições e paráfrases, direcionados a um discurso do cotidiano, com suas crenças e opiniões. Pode-se, aqui, fazer um paralelo com o sujeito usuário divulgador de títulos de divulgação científica e o discurso de divulgação oficial. Nesse caso, são bem mais evidentes o envolvimento pessoal do sujeito usuário em muitas ocasiões e o deslocamento do discurso da ciência em si tem uma distância ainda maior. Porém, o equivalente ao leitor é agora também escritor, produtor e enquadrador de discursos do seu interesse e até por simples frases ou enunciações aforizantes. Ele participa de todo o processo de divulgação de outro modo, ainda mais envolvido e, por isso, o discurso de divulgação científica está tão preocupado em novos modos e estratégias de disseminação da informação, aproveitando as novas tecnologias e as redes sociais. Um cuidado maior se faz não unicamente pelo uso dos recursos tecnológicos, mas pelas práticas dos usuários que projetam um processo de interação, na verdade mais voltado para si mesmo, e mesmo assim trazendo uma intensidade na circulação dos discursos como nunca se vira antes.

\section{REFERÊNCIAS}

AUTHIER, J. La mise em scène de la communication dans des discours de vulgarisation scientifique. Langue Française, Paris, n. 53, p. 34-47, 1982.

GRIGOLETTO, E. O discurso da divulgação científica: um espaço discursivo intervalar. $2005.269 \mathrm{f}$. Tese (Doutorado em Letras) - Instituto de Letras, Universidade Federal do Rio Grande do Sul, Porto Alegre, 2005.

KISHIE, K. Editores discutem desafio da divulgação científica em redes sociais. 2015. Disponível em: $<$ http://www.revistahcsm.coc.fiocruz.br/editores-discutem-desafios-da-divulgacao-cientifica-em-redessociais/>. Acesso em: 15 fev. 2016.

MAINGUENEAU, D. Cenas da enunciação. São Paulo: Parábola, 2008.

. Discurso e Análise do Discurso. Trad. Sírio Possenti. Parábola Editorial, 2015.

. Doze conceitos em análise do discurso. São Paulo: Parábola, 2010.

Frases sem texto. São Paulo: Parábola, 2014.

MELO, L. B. Aforizações em redes sociais: o discurso na interação humano-computador-humnao. In: Proceedings of the 6th Workshop on Human-Computer Interaction Aspects for the Social Web-Anais 2015. ed. 1, v.1, Salvador, nov. 2015.

Memória discursiva em redes sociais: o caso de "bandido bom é bandido morto". In: ALED $\overline{B R A S I L}$ - Anais..., ed. 1, v. 1, n. 3, São Carlos, maio 2014a. Disponível em:

$<$ http://www.revistaaledbr.ufscar.br/index.php/revistaaledbr/article/view/103/97>. Acesso em: 02 out. 2015.

Quando o gigante acorda, vai pra rua e sai do Facebook: frases em movimento. Cadernos de Estudos Linguísticos, v. 56, n. 2, Campinas, jul./dez. 2014b. Disponível em:

$<$ http://revistas.iel.unicamp.br/index.php/cel/article/view/4475/5011>. Acesso em: 01 out. 2015.

ORLANDI, E. P. Divulgação científica e efeito leitor: uma política social urbana. In: GUIMARÃES, E. (Org). Produção e circulação do conhecimento: Estado, mídia, sociedade. Vol. 1, Campinas, SP: Pontes Editores, 2001.

ZAMBONI, L. M. S. Cientistas, jornalistas e a divulgação cientifica: subjetividade e heterogeneidade no discurso da divulgação científica. Campinas: Autores Associados, 2001. 
Recebido em: 27/07/16. Aprovado em: 30/01/17.

Title: Titles in scientific disclosure news: discursive strategies and functionalities in Facebook interface

Author: Lafayette Batista Melo

Abstract: The objective of this article is to understand, through the concept of aphorization, how works the circulation of titles in scientific disclosure news on Facebook. Titles were collected through specific Google search techniques. The results show that in terms of the interface features, some news are highlighted by specific sections, by the use of images and by the titles edition. Regarding the discourse strategies, information can be highlighted taking samples as generalizations, ensuring information as proven, with minor changes in texts of sub-headings and changing the bias of the original text of blogs in its replication on Facebook. Some conclusions: functionalities and discourse strategies work together to strengthen what is said; circulation of information possibilities differ not only in relation to the world outside the digital, but in relation to the web recent history, and media discourse functions are crucial to modify the original information.

Keywords: Title. Aphorization. Circulation. Scientific disclosure. Facebook.

Título: Títulos en noticias de divulgación científica: estrategias discursivas y funcionalidades en la interface del Facebook

Autor: Lafayette Batista Melo

Resumen: El objetivo del trabajo es comprender, a través del concepto de aforización (relativo al aforismo) como funciona la circulación de títulos de noticias de divulgación cientifica en Facebook. Fueron colectados títulos por medio de técnicas de búsquedad especificas en Google. Los resultados muestran que, con relación a funcionalidades de interface, algunas noticias son destacadas por sesiones especificas, por el uso de imágenes y por la edición de títulos. Con relación a las estrategias discursivas, informaciones pueden ser destacadas tomando muestras como generalizaciones, garantizando informaciones como comprobadas, con pequeños cambios de palabras en los subtítulos y cambiando el sesgo del texto original de los blogs en las replicaciones en Facebook. Algunas conclusiones: funcionalidades y estrategias discursivas actúan en conjunto para reforzar dichos; posibilidades de circulación de la relación a la historia reciente de la Web, y funciones del discurso de la media son preponderantes para modificar informaciones originales.

Palabras-clave: Título. Aforización. Circulación. Divulgación científica. Facebook.

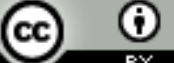

Este texto está licenciado com uma Licença Creative Commons Atribuição 4.0 Internacional. 